\title{
The Challenges of Applying Planetary Boundaries as a Basis for Strategic Decision-Making in Companies with Global Supply Chains
}

Roland Clift ${ }^{1}$, Sarah Sim ${ }^{2, *}$, Henry King ${ }^{2}$, Jonathan L. Chenoweth ${ }^{1}$, Ian Christie ${ }^{1}$, Julie Clavreul $^{2}$, Carina Mueller ${ }^{2}$, Leo Posthuma ${ }^{3,4}$, Anne-Marie Boulay ${ }^{5}$, Rebecca Chaplin-Kramer ${ }^{6}$, Julia Chatterton ${ }^{2}$, Fabrice DeClerck ${ }^{7,8}$, Angela Druckman ${ }^{1}$, Chris France ${ }^{1}$, Antonio Franco ${ }^{2}$, Dieter Gerten ${ }^{9,10}$, Mark Goedkoop ${ }^{11}$, Michael Z. Hauschild ${ }^{12}$, Mark A. J. Huijbregts ${ }^{3,13}$, Thomas Koellner ${ }^{14}$, Eric F. Lambin ${ }^{15,16}$, Jacquetta Lee ${ }^{1}$, Simon Mair ${ }^{1}$, Stuart Marshall ${ }^{2}$, Michael S. McLachlan ${ }^{17}$, Llorenç Milà i Canals ${ }^{18}$, Cynthia Mitchell ${ }^{19}$, Edward Price ${ }^{2}$, Johan Rockström ${ }^{20}$, James Suckling ${ }^{1}$ and Richard Murphy ${ }^{1}$

1 Centre for Environment and Sustainability, University of Surrey, Guildford GU2 7XH, UK; r.clift@surrey.ac.uk (R.C.); j.chenoweth@surrey.ac.uk (J.L.C.); i.christie@surrey.ac.uk (I.C.); a.druckman@surrey.ac.uk (A.D.); c.france@surrey.ac.uk (C.F.); j.lee@surrey.ac.uk (J.L.); s.mair@surrey.ac.uk (S.M.); j.suckling@surrey.ac.uk (J.S.); rj.murphy@surrey.ac.uk (R.M.)

2 Unilever Safety and Environmental Assurance Centre, Unilever R\&D, Colworth Science Park, Sharnbrook MK44 1LQ, UK; henry.king@unilever.com (H.K.); julie.clavreul@unilever.com (J.C.); carina.mueller@unilever.com (C.M.); julia.chatterton@unilever.com (J.C.); antonio.franco@unilever.com (A.F.); stuart.marshall@unilever.com (S.M.); edward.price@unilever.com (E.P.)

3 Department of Environmental Science, Institute for Water and Wetland Research, Radboud University Nijmegen, Heyendaalseweg 135, 6525 AJ Nijmegen, The Netherlands; L.Posthuma@science.ru.nl or Leo.Posthuma@rivm.nl (L.P.); M.Huijbregts@science.ru.nl (M.A.J.H.)

4 Centre for Sustainability, Environment and Health (DMG), National Institute for Public Health and the Environment (RIVM), P.O. Box 1, NL-3720 BA Bilthoven, The Netherlands

5 CIRAIG, Polytechnique Montreal, Department of Chemical Engineering, P.O. Box 6079, Montreal, QC H3C 3A7, Canada; anne-marie.boulay@polymtl.ca

6 Natural Capital Project, Woods Institute for the Environment, Stanford University, 371 Serra Mall, Stanford, CA 94305, USA; bchaplin@stanford.edu

7 The Earth Institute, Columbia University, New York, NY 10027, USA; f.declerck@cgiar.org

8 Agrobiodiversity and Ecosystem Services Programme, Bioversity International, Parc Scientifique Agropolis, 34397 Montpellier, France

9 Research Domain of Earth System Analysis, Potsdam Institute for Climate Impact Research, Telegrafenberg, 14473 Potsdam, Germany; gerten@pik-potsdam.de

10 Geography Department, Humboldt-Universität zu Berlin, Unter den Linden 6, 10099 Berlin, Germany

11 PRé Consultants bv, Stationsplein 121, 3818 LE Amersfoort, The Netherlands;

Goedkoop@pre-sustainability.com

12 Department of Management Engineering, Technical University of Denmark, DK-2800 Kgs. Lyngby, Denmark; mzha@dtu.dk

13 PBL Netherlands Environmental Assessment Agency, Bezuidenhoutseweg 30, 2594 AV The Hague, The Netherlands

14 Faculty of Biology, Chemistry and Geosciences, BayCEER, University of Bayreuth, Universitätsstr. 30, 95440 Bayreuth, Germany; thomas.koellner@uni-bayreuth.de

15 Georges Lemaître Earth and Climate Research Centre, Earth and Life Institute, Université catholique de Louvain, 3 place Pasteur, B-1348 Louvain-la-Neuve, Belgium; elambin@stanford.edu

16 School of Earth, Energy \& Environmental Sciences and Woods Institute for the Environment, 473 via Ortega, Stanford University, Stanford, CA 94305, USA

17 Department of Environmental Science and Analytical Chemistry (ACES), Stockholm University, SE-10691 Stockholm, Sweden; michael.mcLachlan@aces.su.se

18 Division of Technology, Industry and Economics, UNEP, 1 Rue de Miollis, 75015 Paris, France; Llorenc.Mila-I-Canals@unep.org 
19 Institute for Sustainable Futures, University of Technology of Sydney, P.O. Box 123, Broadway, NSW 2007, Australia; Cynthia.Mitchell@uts.edu.au

20 Stockholm Resilience Centre, Stockholm University, Kräftriket 2b, 10691 Stockholm, Sweden; johan.rockstrom@su.se

* Correspondence: sarah.sim@unilever.com; Tel.: +44-123-426-4947

Academic Editor: Marc A. Rosen

Received: 22 December 2016; Accepted: 8 February 2017; Published: 15 February 2017

\begin{abstract}
The Planetary Boundaries (PB) framework represents a significant advance in specifying the ecological constraints on human development. However, to enable decision-makers in business and public policy to respect these constraints in strategic planning, the PB framework needs to be developed to generate practical tools. With this objective in mind, we analyse the recent literature and highlight three major scientific and technical challenges in operationalizing the PB approach in decision-making: first, identification of thresholds or boundaries with associated metrics for different geographical scales; second, the need to frame approaches to allocate fair shares in the 'safe operating space' bounded by the PBs across the value chain and; third, the need for international bodies to co-ordinate the implementation of the measures needed to respect the Planetary Boundaries. For the first two of these challenges, we consider how they might be addressed for four PBs: climate change, freshwater use, biosphere integrity and chemical pollution and other novel entities. Four key opportunities are identified: (1) development of a common system of metrics that can be applied consistently at and across different scales; (2) setting 'distance from boundary' measures that can be applied at different scales; (3) development of global, preferably open-source, databases and models; and (4) advancing understanding of the interactions between the different PBs. Addressing the scientific and technical challenges in operationalizing the planetary boundaries needs be complemented with progress in addressing the equity and ethical issues in allocating the safe operating space between companies and sectors.
\end{abstract}

Keywords: planetary boundaries; biodiversity; climate change; chemical pollution; water use; business

\title{
1. Introduction: Sustainability-Recognising Constraints
}

It is widely accepted that for human activities to be sustainable, we must respect the ecological constraints on what we can do on and with planet Earth. Rockström et al. [1] proposed a way of defining a 'safe operating space for humanity' in terms of a set of Planetary Boundaries (PBs), each framed in scientific terms: the idea being that keeping human activities within the PBs can maintain the Earth in the 'Holocene-like' state in which human societies have developed for millennia. The PB approach is based on scientific evidence on the likely resilience of various of the Earth's systems in response to a set of environmental pressures, but encompasses value judgment in setting the target limits within the range of uncertainty between 'safe' and 'dangerous' [2]. This framework opens up ways to conceptualise and operationalise what we term 'absolute environmental sustainability', with carrying capacity used as the benchmark to compare environmental impacts to what could be sustainable [3]. This contrasts with most current approaches to environmental management, such as comparative Life Cycle Assessment of products and services [4], which focus on reducing relative unsustainability. An approach to reconciling the social foundations of human development with the PBs has been proposed by Raworth [5] and Dearing et al. [6].

The PBs and the social foundations for just use of the safe operating space set out a basis in natural and social science for conceiving sustainable development trajectories, but they are framed at a high conceptual level and are global in scale. For operational decision-making, the PBs must be defined at an appropriate geographical scale, with metrics to indicate whether a PB has been or is likely to be 
transgressed. Approaches proposed in the literature have been directed mainly at specific geographical areas (Section 2.1) with little consistency between the various approaches [7]. Furthermore, a normative basis is needed for justice in the allocation of the environmental space for at least three classes of user: individuals, producing entities (e.g., industry), and governments [3,8,9]. Some normative principles have been proposed $[7,10,11]$, drawing on the work of others including the Intergovernmental Panel on Climate Change [12], but there is as yet no agreed mechanism or basis to allocate the space.

This paper explores the challenges in operationalizing the PBs approach for application in industry or other organisations. The work originated with Unilever, a multinational company in the Fast-Moving Consumer Goods (FMGC) sector. Companies providing goods and services are particularly significant through the decisions they make in designing products and managing supply chains that may link together different regions and impact many, if not all, PBs [13]. Unilever is merely one example of a company that manages global supply chains and the conclusions and observations reached here apply much more generally. The focus here is on strategic planning and decisions which have large scale and long-term implications and impacts, as distinct from operational decisions: examples are developing new business areas which decouple growth from impact, rather than introducing specific new products; changing manufacturing technologies rather than making modifications to existing processes; and switching materials across a whole business area, as distinct from an ingredient change in a single product. The paper highlights gaps in understanding and scientific consensus, and outlines priority areas for further research to enable implementation of the PB concept. We recognise that there are complex, systemic interactions between the PBs but to facilitate strategic decision-making, the boundaries need to be assessed individually. We start from the PBs proposed by Rockström et al. [1] and Steffen et al. [2] and eschew aggregation of PBs typified by other approaches such as the Ecological Footprint [14-16]. We explore how four of the boundaries might be operationalized: (1) climate change; (2) freshwater use; (3) biosphere integrity and (4) chemicals and other novel entities. The latter three are boundaries with a regional dimension, in contrast to climate change where, although the impacts may be different across regions, the contributions/activities are mediated globally. Section 2 outlines the challenges in applying a PB-based framework across a commercial sector. Subsequent Sections 3-6 focus on the four specific boundaries. Section 7 compares approaches to defining the boundaries and the prospects for governing the 'safe operating spaces' and allocating them between different activities. Section 8 presents general conclusions and prospects for further developments.

\section{The Planetary Boundaries Framework}

\subsection{Challenges in Operationalising the Planetary Boundaries Framework}

The planetary boundary framework offers a global 'dashboard' of 'control variables' for vital Earth system processes [1,2]. We recognize the immense geo-political, normative and behavioural problems in applying the $\mathrm{PB}$ approach but consider that commercial organizations must be engaged in this even though the integrated solutions lie outside the mandate and power of individual companies $[17,18]$. Translating PBs into a system of principles, tools and metrics for strategic business planning consistent with maintaining a resilient 'safe and just operating space' raises three major challenges, set out below:

(1) The high-level, global PB parameters must be translated into practical metrics that may require definition at a regional or local scale. This is recognised in Steffen et al.'s [2] revision of the PB framework. Approaches have been suggested for national, regional and local planning, for example for Sweden [19], Switzerland [20], Canada and Spain [17]. However, if the metrics are to be used by industry, they will require a common framework even when they refer to local or regional scale, and such a framework has yet to emerge [7]. There is the further difficulty that (un)sustainability is an emergent property of a complex system and is multi-scale: exceeding local-scale boundaries in several locations can lead to cumulative global impacts that exceed the sum of the local effects. 
(2) Even if the 'safe operating space' within each PB can be defined and quantified at an appropriate scale, a basis is needed for allocating 'fair shares' of the space to individual activities and enterprises. This challenge is related to that of negotiating a consensual ethical and political basis for allocating the 'safe operating space' between nations, producers and individuals, introduced in Section 1. It requires an extensive and inclusive deliberative approach as illustrated by institutional approaches on climate change and the Global Goals for Sustainable Development (SDGs) [21]. Any such framework must also be capable of providing a basis for strategic company planning. The Science-Based Targets initiative [22] for climate change, discussed further in Section 3, provides one example of how the 'safe operating space' might be defined and allocated for a global boundary.

(3) Implementation of measures to respect the Planetary Boundaries depends on bodies which may currently exist at national or regional scales but not yet at the global scale. Of the four PBs explored here, climate change and biodiversity have international bodies setting targets and attempting to promote actions, but even here the history of implementation to remain within boundaries is not encouraging. The global coordination of progress towards the SDGs and more generally the 2015-2030 Development Agenda [23] offers an opportunity to bring together such implementation beyond the national level, encompassing contributions by the private sector. Common metrics linking specific SDGs to the Planetary Boundaries would facilitate global coordination and alignment of commitments and actions.

In this paper we concentrate on the first of these challenges and also provide some suggestions on how the second might be addressed. Meeting the third challenge is beyond the scope of the paper but we recognise that companies have an important role in ensuring that governance bodies and approaches are well-founded and practical.

\subsection{Planetary Boundaries for Business Application}

Efforts by the business community to understand, manage, and reduce the environmental impacts of products generally rely on analyses such as Life Cycle Assessment (LCA) [24], although current practice is to assess relative rather than absolute (un)sustainability to reduce their environmental impacts. That is to say, corporate sustainability is typically benchmarked against prior performance and corporate objectives, rather than against global or local metrics representing ecological limits. By adopting a life cycle approach companies can consider the impacts of their products from sourcing through to their use and disposal. Applying this principle to absolute sustainability implies that all activities, supply chains and uses of a company's products should lie within their share of the PB safe operating space. Determining this will require large amounts of data, spanning multiple geographical regions for many value chains.

We suggest that there are two possible ways to integrate the $\mathrm{PB}$ concept into business planning to decouple growth from impact. Firstly, PBs could be used within Life Cycle Impact Assessment, e.g., to develop a 'PB-informed' approach which will be particularly relevant for establishing 'PB-compliant' assessments of products and services. Several research groups and companies are already working on this topic [25-29]. A second approach is to develop a range of complementary indicators or tools, particularly relevant for strategic company, portfolio and sectorial assessment and management. We focus here on this second approach, suggesting that LCA and related analyses should be improved and expanded to facilitate predictive assessment, pointing to early warning signals or non-linear relationships between corporate growth and environmental impacts [30-35].

\subsection{Cross-Disciplinary Perspectives}

To explore the challenges for business-level application of the PB framework, we focus on four of the boundaries: climate change, freshwater use, biosphere integrity and chemicals and other novel entities. These categories exemplify a range of issues in their practical application (definition of 
boundary and measurement) as well as governance. Table 1 summarises the biophysical scales at which the four Planetary Boundaries explored here must be interpreted along with the quantitative definition of each PB proposed by Rockström et al. [1] and Steffen et al. [2]. It also lists several governance organisations for each $\mathrm{PB}$, along with the values currently used as the basis for policy, regulation and planning where these exist. As a general point, in the absence of international structures to manage the available space, implementation depends on voluntary action in response to clear and specific targets.

Table 1. Comparison of the four Planetary Boundaries (PBs).

\begin{tabular}{|c|c|c|c|c|}
\hline PB & $\begin{array}{l}\text { Biophysical } \\
\text { Scales: }\end{array}$ & Proposed Planetary Boundary [2] & Current Operational Boundary & Existing Governance Organisations \\
\hline Climate change & Global & $\begin{array}{c}350 \text { ppm CO2-equivalents } \\
\text { aggregated across greenhouse gases } \\
\text { using IPCC's GWP100 }\end{array}$ & $\begin{array}{l}1.5 / 2{ }^{\circ} \mathrm{C} \text { temperature rise, } \\
\text { interpreted as } 450 \mathrm{ppm} \text { CO2e [12] }\end{array}$ & $\begin{array}{l}\text { Global organization: UNEP IPCC } \\
\text { Operational: World Wildlife Fund } \\
\text { (WWF); World Resources Institute } \\
\text { (WRI); Science-Based Targets (SBT) }\end{array}$ \\
\hline Freshwater use & $\begin{array}{l}\text { Regional/ } \\
\text { Local }\end{array}$ & $4000 \mathrm{~km}^{3} /$ year & $\begin{array}{l}\text { No operational global boundary: } \\
\text { River basin and local boundaries } \\
\text { operational in some regions }\end{array}$ & $\begin{array}{l}\text { UN-Water; Global Water Partnership; } \\
\text { World Water Council; etc. }\end{array}$ \\
\hline
\end{tabular}

For each PB category, we analyse how the environmental space within the boundary can be defined and measured and propose practical indicators and further research needs. Looking across the four PBs reviewed here, we set out the challenges in specifying the 'safe operating space' in decision-making tools which can be operationalized by companies and other organisations recognising the need to respect absolute sustainability.

\section{Climate Change}

\subsection{Defining and Measuring the Safe Operating Space}

Of the four Planetary Boundaries discussed here, climate change has received the most scientific attention through the Intergovernmental Panel on Climate Change [36], feeding directly into international policy. Unlike the other three PBs selected, climate change is truly planetary: climate-forcing gases have impacts that do not depend on the location of their source. The IPCC has indicated global targets for the mitigation of greenhouse gas (GHG) emissions [37] and explored ways in which mitigation can be achieved [12]. Possible global governance mechanisms have been debated, for example at the 21st Session of the Conference of the Parties UNFCCC (COP21) meeting in December 2015.

The boundary for climate change is conventionally quantified as an atmospheric concentration of GHGs [37]. Setting the concentration limit is more contentious and illustrates a general problem in defining PBs: the limit is not defined by a single 'tipping point' beyond which the probability of catastrophic climate change becomes unacceptable. Rather, the effects of climate change emerge from a number of specific tipping points (e.g., the tipping point for loss of Arctic ice has already been surpassed [36]) and from impacts that increase progressively as GHG concentration rises. The climate change boundary is in the range $400-500 \mathrm{ppm} \mathrm{CO}_{2 \mathrm{e}}\left(\mathrm{CO}_{2}\right.$ equivalents) of which $350-450 \mathrm{ppm}$ is carbon 
dioxide [1,2]. If the limit is intended to represent a compromise which preserves the possibility that the system can restore itself in the long term, it is appropriate to set the concentration boundary by deliberation according to the precautionary principle implied in the PB concept, based on the scientific evidence but recognising the uncertainties; i.e., regarding this as a case for application of the approach known as 'post-normal science' [38] in which science intended to inform policy is subject to review by an extended group including non-expert stakeholders. International negotiations exemplified by COP21 can then be seen as post-normal science in action, so that the outcome should be accepted as delineating the operating space within which the shares for individuals, companies and nations are to be allocated. The current consensus is that the target limit should be in the middle of the PB range at 450 ppm $\mathrm{CO}_{2 \mathrm{e}}$ ([12] Figure SPM4 and Table SPM.1), consistent with the policy agreement at COP21 to base policy on limiting global temperature change to 1.5 to $2{ }^{\circ} \mathrm{C}$. We apply the same figure for strategic company planning. The challenge is then to reconcile a company's commercial aspirations with the boundary of $450 \mathrm{ppm} \mathrm{CO}_{2 \mathrm{e}}$.

\subsection{Practicality of Applying Indicators for Climate Change}

Working back from a target maximum concentration enables the total permissible emissions in some prescribed time period to be estimated, in terms of equivalent quantities of carbon dioxide $\left(\mathrm{CO}_{2 \mathrm{e}}\right)$ [39]. In principle, these permissible quantities can be translated into a per capita annual figure, representing a notional 'personal allocation' of GHG emissions, although any such rationing system is likely to be impractical and politically unacceptable and therefore seems remote. As a potentially more practical approach, such estimates have been used in the 'contract-and-converge' approach to allocating GHG emissions between different countries [40,41] by estimating their expected future population and hence permissible national emissions. Recognising and apportioning tolerable GHG emissions is also the basis for the Science-Based Targets (SBT) approach [22], adopted by 179 companies globally at COP21 and using the $450 \mathrm{ppm} \mathrm{CO}_{2 \mathrm{e}}$ boundary. In spite of the relative transparency of this approach, it still contains some uncertainties, notably over whether GHG targets should be based on the emissions from a country (production basis) or on the life cycles of goods and services consumed within the country (consumption basis) [42]. International policy discussions have focussed on production-based accounting, which underestimates the emissions associated with consumption in countries which import materials, food and manufactured goods. However, for most companies, the consumption basis seems more appropriate, as is recognised in the Science-Based Targets.

\subsection{Further Research}

Company planning should be on the same accounting basis as international policy and negotiations; i.e., the approach recommended by IPCC based on radiative forcing integrated over a period of 100 years. If atmospheric GHG concentration and hence permitted GHG emissions are accepted as the basis for measurement and management of the PB for climate change, then key areas for future research include extending the approach beyond the energy-intensive sectors currently represented in the Science-Based Targets to other activities with high GHG and often highly uncertain emissions, notably agriculture and deforestation. These include non-fossil fuel-derived emissions such as those from land use change (change in carbon stocks of biomass and soils), methane from ruminants and certain agricultural practices and crops (e.g., flooded rice production) and also nitrous oxide from application of fertilizers and animal waste to soil. Related to this, broader research is required to understand the impacts of climate change on agricultural productivity and subsequent feedbacks in terms of GHG emissions. This will require forecasting of land-use changes resulting from business decisions (also noted in Section 4.3) and climatic influences and scientific estimation of the resulting emissions. The processes underlying this PB relate to other processes and effects; the effects of climate change on biodiversity and ecosystem functioning and on water availability are particularly significant for further research. 


\section{Freshwater use}

\subsection{Defining and Measuring the Safe Operating Space}

Measures of water use distinguish between 'blue water' (i.e., streams, aquifers and other water bodies) and 'green water' (i.e., precipitation used directly by plants or evaporated from soil without entering a stream or aquifer) [43]. The original intention for the PB on freshwater resources was 'to safely sustain enough green water flows for moisture feedback (to regenerate precipitation), allow for the provisioning of terrestrial ecosystem functions and services (e.g., carbon sequestration, biomass growth, food production), and secure the availability of blue water resources for aquatic ecosystems' [1]. However, the boundary outlined in Rockström et al. [1] and retained in Steffen et al. [2] refers only to blue water consumption as an aggregate proxy for human interference within river catchments. Their estimate is based on Postel et al.'s [44] estimate of renewable accessible global freshwater resources as $12,500 \mathrm{~km}^{3}$ per year, combined with the assumption that $30 \%$ of river flow needs to remain to sustain aquatic ecosystems while another $30 \%$ must be maintained to avoid critical water scarcity. Allowing for an uncertainty range of $\pm 1000 \mathrm{~km}^{3}$ /year, the $P B$ proposed was $4000 \mathrm{~km}^{3}$ /year of water consumed, i.e., abstracted and not returned to the same drainage basin.

However, basing the boundary for water consumption on global estimates has limited value [45] since extraction rates have long passed safe ecological limits in some places but remain well below safe limits in others. Steffen et al. [2] recognised that water use should be assessed on a river basin scale. Their definition of regional boundaries for water use seeks to ensure that withdrawals in all river basins leave sufficient water to ensure a 'fair-to-good' aquatic ecosystem state. Pastor et al. [46] reviewed five potential environmental flow requirement methodologies as applied to 11 case study river basins, and concluded that the Variable Monthly Flow (VMF) method gave the most reliable local estimates of flows that can be related to use within the 'safe space'. Steffen et al. [2] therefore recommend the VMF method for calculating boundaries for water withdrawals at the basin scale. They propose boundaries for average monthly blue water withdrawal in river basins at the lower end of the uncertainty ranges they obtained: $25 \%$ of mean monthly flow for periods of low flow, $40 \%$ for periods of intermediate flow and 55\% for periods of high flow. These boundaries are conservative, taking some account of temporal variations in water availability but accounting only roughly for spatial variations in ecosystem requirements which depend on local biophysical and habitat conditions. Given the large uncertainty ranges, spatially explicit boundaries informed by more detailed assessments [47] would help in company decision making, including siting and sourcing decisions in particular.

We suggest that the global concept should be expressed as regional boundaries for consumptive use. Whilst water withdrawal may cause some ecosystem disturbance, this may be partially mitigated if water of similar quality is returned close to the point of withdrawal $[48,49]$. This is frequently the case for cooling water used in electricity generation, which can account for $40 \%$ of withdrawals in industrialised countries but is mostly returned to its source [50]. Further work is underway to propose a revised global PB value for water use on the basis of aggregated local or regional boundaries: Gerten et al. [51] suggest an initial procedure for a bottom-up calculation based on spatially explicit assessments of environmental flow requirements, following Pastor et al. [46].

\subsection{Practicality of Applying Indicators of Water Use}

Recognising that safe operating limits for global freshwater use must be geographically and temporally referenced, we focus here solely on basin-scale boundaries. Maps provided by Steffen et al. [2] could be used for initial screening of watersheds of concern, acknowledging that they are based on water withdrawals rather than consumption and that factors other than environmental flow requirements may be important to define the safe operating space (e.g., the sustenance of green water flows, see PB definition above). They could be used to identify basins where withdrawals are currently well below the boundary and future water-intensive production could be located. 
Given the preference for considering consumptive water use, we highlight the indicator called AWARE (Available Water Remaining), recently developed by Boulay et al. [52] to compare current human water consumption to the volume of water available after meeting ecosystem water requirements estimated by the approach of Pastor et al. [46]. The AWARE indicator identifies locations and months where human consumption exceeds the allowable volume of water use. However, AWARE is formulated as an index; to use the approach to determine the impact of specific local activities would require information expressed as available volume.

\subsection{Further Research}

Further work is needed to refine the water boundary and adapt it to business decision-making. As noted above, the local boundary should be expressed in terms of consumptive use rather than withdrawal. The basin scale boundaries in Steffen et al. [2] were defined for three archetypes (low, intermediate and high river flows) acknowledging temporal flow variations; however, local relevance also requires differences in environmental flow requirements between basins to be recognised. Further development of the boundary definition should aim to achieve for all surface water bodies the ecological status that maintains ecosystem functions and services and avoids exceeding tipping points (linking to PB of biosphere integrity metrics). In addition, the current PB framework does not explicitly address the problem of overuse of groundwater which takes longer than surface water to recharge. Further work could aim at defining local to regional limits for groundwater use designed, for example, so that use rates do not exceed renewal rates.

Interactions with other PBs should also be considered and quantified, in particular interactions with land use change can indirectly impact the amounts of blue water available in a basin [53-55], and with the climate change boundary as climate change will affect water availability and demand $[56,57]$. Via the role of water volume in diluting threats such as those of toxic chemicals or nutrients, there is also a link with the PB for chemical pollution.

Finally, improved models are also needed for predicting future availability and consumption. As companies try to meet the needs of a growing population under conditions of changing climate and land use constraints, water resources will come under increasing pressure; companies therefore need tools which enable them to forecast impacts and mitigation options. Some of the consequences of these pressures on water resources can now be quantified with global coupled hydrology-vegetation models [51], but they have yet to be integrated into boundary definition and allocation of the safe operating space.

\section{Biosphere Integrity}

\subsection{Defining and Measuring the Safe Operating Space}

Rockström et al. [1] attempted to set a boundary for 'safe' rates of extinction (i.e., loss of species) and hence identified 'rate of biodiversity loss' as one of the three PBs already violated. The biosphere integrity boundary is particularly closely associated with the boundary for chemical pollution (and/or 'novel entities'; see Section 6) as both affect earth system integrity via impacts on biodiversity, though biosphere integrity has been focused on terrestrial systems (Rockström et al. [1] and Steffen et al. [2]) and chemical pollution on aquatic. Here we continue to address the two boundaries separately.

The validity of framing the boundary in terms of extinction rates has been much debated [34,58]. Rockström et al. [1] themselves concluded that 'science is, as yet, unable to provide a boundary measure that captures, at an aggregate level, the regulating role of biodiversity' and suggested that extinction rate is only an interim proxy indicator. Steffen et al. [2] redefined the boundary as 'biosphere integrity', developing the original concept into a 'two-component' approach-genetic and functional diversity-because large changes in either component could push the Earth system out of the 'Holocene-like state' and compromise its ability to sustain human societies as we know them. Even with this two-component approach, Steffen et al. [2] conclude that understanding is still 
insufficient for a fully representative definition and measurement of biodiversity. Like those proposed by Rockström et al. [1], their suggested indicators are for 'interim use'.

Genetic diversity focuses on long-term ability to persist or adapt to environmental changes: i.e., the ability of the biosphere or ecosystems to continue to function in the face of external pressures such as climate change. Steffen et al. [2] conceive of genetic diversity (i.e., variety within species and number of different species, sometimes referred to as species richness and diversity) as an 'information bank' embodying the collective evolutionary history of the species found globally and representing a valuable future source of bioactive compounds (e.g., pharmaceuticals) or species (e.g., crop varieties) better adapted to future climates and conditions. Following Rockström et al. [1], Steffen et al. [2] retain extinction rate as the indicator for loss of genetic diversity.

Functional diversity, in contrast, focuses on ecosystem capacity to provide essential life-supporting functions, including global metabolic processes such as evapotranspiration, carbon capture and nutrient cycling. Higher functional diversity has been linked to greater primary productivity [59], increased drought resilience [60], increased crop yields due to plant species interactions [61] or enhanced levels of crop pollination [62], improved control of agricultural pests by natural enemies [63], and increased resistance to invasion [64,65]. Steffen et al. [2] recommend the Biodiversity Intactness Index (BII), proposed by Scholes and Biggs [66], as an interim indicator of functional diversity; the BII measures the average abundance of a large and diverse set of organisms in a given geographical area, relative to their reference populations. However, functional diversity relates to preservation of one or more specific functions; it therefore requires identification of the functions of concern and of the species pool that provides them. By contrast, BII is an index of community intactness not related to any specific function and therefore not strictly reflecting functional diversity. Even so, intactness may be a good proxy measure of a community's capacity to provide a function; indeed, recent evidence suggests that 'losses of local species richness exceeding 20\% are likely to substantially impair the contribution of biodiversity to ecosystem function and services, and thus to human well-being' [67].

\subsection{Practicality of Applying Indicators of Biosphere Integrity}

The simplified interim indicators in Table 1 present challenges to attempts to operationalise them for business decision making, not least in the limited ability to measure and interpret them given poor data quantity and availability and contention over quantification of the PB [68].

For genetic diversity, there are significant challenges to operationalising the extinction rate indicator suggested by Rockström et al. [1] for business decision-making: it is difficult to conceive of direct cause-effect pathways to link specific innovation, procurement or supply chain decisions through to species extinction at the global (or indeed any) scale. A model linking land use to species loss has been proposed by Chaudhary et al. [69]; it has been recommended by the UNEP/SETAC Life Cycle Initiative [70] as an interim indicator of genetic diversity, given its comprehensive global coverage. This model uses Species-Area Relationships (SAR) to express vulnerability as the ratio of threatened endemic richness (number of 'irreplaceable' species) to the total species richness hosted by the region [71]. However, whilst Chaudhary et al.'s [69] indicator estimates potential species loss at regional and global scales, it does not suggest boundaries for the maximum species loss that would mark potentially critical species-loss fractions.

For functional diversity, the BII metric [2] can potentially be applied at multiple scales (in terms of geographic extent and also resolution), but it requires extensive data to establish baselines and current status. Newbold et al. [72] demonstrate significant advances made through the PREDICTS project (Projecting Responses of Ecological Diversity In Changing Terrestrial Systems) [73], whose researchers have compiled presence-absence and abundance data for a vast array of species in thousands of sites around the world, and concluded that the impacts on biodiversity intactness within most biomes, biodiversity hotspots and even some wilderness areas are already beyond the boundary (taking the precautionary limit of $10 \%$ reduction in BII-see Table 1). The PREDICTS database represents the most complete coverage of biodiversity response to human activity currently available, advancing 
beyond previous meta-analyses (e.g., GLOBIO) [74], but limitations remain, especially for facilitating future projections of biodiversity resulting from changes in land use or other changes arising from corporate decisions such as choice and sourcing of raw materials. First, further work is required to understand the behaviour and functioning of ecosystems globally (including native and non-native species) based on the empirical observations. This understanding is required to establish the sensitivity of different ecosystems to different drivers and identify the specific control variables for biodiversity loss in different systems [75,76]. Second, globally-generalised theoretical models for biodiversity are required to complement correlative models such as PREDICTS for predicting and mitigating future biodiversity loss and ecosystem functioning so that effects of novel changes can be predicted; a first attempt is presented by Harfoot et al. [77]. Third, there are gaps in data coverage, especially across boreal forests, flooded grasslands, savannahs and mangroves, and across Africa in general, where much of the most rapid land-use change is occurring. Certain species (e.g., those dwelling in soil and canopies) are also routinely under-represented in the literature and hence also in this database $[72,78]$. These gaps in geographic and species coverage currently limit the types of impacts from business decisions this approach is capable of representing.

\subsection{Further Research}

There is still much work to be done to move these biodiversity indicators from interim and conceptual to final and operational. The SAR model for tracking or predicting species losses has not been widely applied, and requires full information on the location of the land used. However, as supply chains are complex and globalised, the data necessary are often unavailable. Whilst significant progress has been made in terms of operationalizing the BII indicator, most recently in Newbold et al. [72], there are a number of areas which require more work to enable application in business decision making. Firstly, whilst the BII can potentially be applied at multiple geographic scales, boundaries have so far only been suggested tentatively and at the global scale; less uncertain boundaries are needed for different spatial units, land cover types and intensities of human use. Second, the BII has so far only been applied to describe the impacts on biodiversity of current land use (i.e., the fraction of area that has already been converted from its original state within specific biomes). This research needs to be complemented by work to predict impacts on biodiversity of future land use change: i.e., the fraction of area that will be converted, or restored, as a result of potential future population, policy, sector or company scenarios; or changes to biodiversity resulting from climate change impacts and anthropogenic responses. Assessment of both current and future biodiversity loss associated with company decisions will require greater supply chain transparency to enable companies to verify the sources of their commodities, to identify where and within which boundaries impacts will occur, and decision-making tools which leverage the data, science and models. These models and underlying data must be open and readily accessible by businesses if they are to be deployed widely [79].

Particularly for predictive assessment, general and accessible land change models (LCMs) are necessary [80] so that companies can explore land use changes likely to result from future sourcing and supply chain decisions. A first step is to adapt econometric equilibrium models to predict how future changes in purchasing decisions will translate to different production patterns. The resulting predictions are typically at too coarse a scale to capture the full impacts of changes in land use. A further step is therefore needed to predict land use change at finer resolutions, in order to capture the impacts of fragmentation or other habitat configuration on biodiversity within a landscape [81,82]. However, models that predict land use change at a country or state level (e.g., through economic modelling) may be more practical, since existing land change models are often proprietary or complex, with locally specific parameterisations which make them difficult to apply by multinational companies making global decisions. Thus, methods or indicators used to quantify future impacts of land use change on biodiversity need to be sensitive to changes in biodiversity at these larger geographical scales to be useful for business decisions. 


\section{Chemical Pollution and Other Novel Entities}

\subsection{Defining and Measuring the Safe Operating Space}

Rockström et al. [1] listed 'chemical pollution' as one of the boundaries for which continued impacts could erode the resilience of ecosystems, based on the concept that the Earth has a finite assimilative capacity. They interpreted chemical pollution to include persistent as well as biodegradable chemicals and argued that it is necessary to take a precautionary approach but did not indicate how to define a boundary. Steffen et al. [2] extended the definition of the PB to cover all 'novel entities' released into the environment including also modified life forms such as Genetically Modified Organisms (GMOs). Here we focus on chemical pollution, as it is better defined in management policies and regulation [83].

Anthropogenic chemical emissions affect several of the planetary boundaries, from physico-chemical processes relating to climate change, ozone depletion and ocean acidification to ecotoxicological effects on biodiversity [1]. There may also be other potential yet unknown effects on Earth system processes [84]. Given the widespread and dispersive use of chemicals in society, toxicological impacts of chemical mixtures on ecosystems have received attention within the PB concept since 2012 [85]. Whilst ecotoxicological impacts of chemicals are one component of the biosphere integrity boundary (see Section 5), the large variability of the problem, the occurrence of ecotoxic effects and the prominence of chemicals in commerce and regulation suggest that a distinct boundary for chemical pollution should be retained to effectively safeguard transgressing the biodiversity boundary, and it may also provide valuable insights for other PBs.

'Defining and measuring the space' has a long history for this boundary [86] and the complexity of the chemical space has led to a range of protective and curative policies, as reviewed recently by Geiser [83]. Since evidence of side-effects of chemicals on wildlife first became evident to the public between the 1940s and 1960s, policy makers explored regulatory tools to chemical management based on a risk rather than an effect-based paradigm (later condensed in e.g., U.S. NRC [87]). In effect, the boundary was defined such that environmental concentrations do not harm the structural or functional integrity of ecosystems, determined from laboratory toxicity studies for individual compounds with a suite of test species. Approaches to risk-based chemical management have been implemented in various jurisdictions (e.g., single countries, EU, OECD) since the 1980s [88-90] with increasing responsibility placed on industry [91]. Protective policies of this type establish a safe boundary that protects ecosystems from the adverse effects of single chemicals. Certain chemical types received extra attention, associated with their environmental behaviour and ecotoxicological properties. Environmental persistence is one of these properties considered of high relevance due to potential legacy effects, and a global regulation has been implemented as a preventive governance framework for persistent compounds (the Stockholm Convention on Persistent Organic Pollutants).

To address chemical pollution in the PB concept, a comprehensive measure of chemical stress is required, similar to the $\mathrm{CO}_{2}$-equivalents $\left(\mathrm{CO}_{2 \mathrm{e}}\right)$ metric to aggregate greenhouse gases for the climate change PB. The metric proposed for mixture impacts is 'mixture toxic pressure', expressing the fraction of species affected by a mixture [92]. Species and ecosystems are exposed to mixtures of chemicals which can act additively, synergistically or antagonistically on species and ecosystems [93]. Persson et al. [84], MacLeod et al. [94] and Diamond et al. [95] highlighted some of the key scientific challenges of establishing a planetary boundary for chemical pollution, including the large number of commercial chemicals, the diversity of associated life cycles, and the complex linkages between emissions, exposure and adverse effects across species, ecosystems, and possibly planetary-scale processes. Simple life cycle based comparative chemical screening tools, such as GreenScreen [96] do not address actual environmental burdens nor the ecotoxicity boundary. Indicators of aggregated ecotoxicological stress have been proposed to complement single chemical risk-based approaches for managing chemicals in the environment $[97,98]$. We acknowledge that such approaches are inconsistent with our recommendations for assessing biosphere integrity. However, if we wish organisations 
to manage chemical pollution this may be the most efficacious approach; it is compatible with regulatory systems in force in some regions to manage water quality and to set localised boundaries for chemical pollution.

\subsection{Practicality of Applying Indicators for Chemical Pollution}

Two indicators of aggregated chemical pollution have been proposed recently, based around the same basic input data (exposure and ecotoxicity data), models and concepts. The first is the chemical footprint methodology [97], which expands on the simpler 'Grey Water Footprint' method [99] and the Critical Dilution Volume method used in life cycle impact assessment for ecolabelling in the EU. This method has been described as an extension of conventional risk assessment to include mixture effects in a representative environmental scenario. For a certain geographical scope and chemical space considered it involves: the estimation of chemicals emission volumes; the estimation of environmental concentrations using physico-chemical and environmental properties as inputs to a multi-media fate model; the collection of ecotoxicity data to determine Species Sensitivity Distributions [90]; the derivation of (mixture) toxic pressures (i.e., the multi-substance Potentially Affected Fraction of species, msPAF) to quantify the toxicity of the resulting mixtures of chemicals, acknowledging similar and dissimilar modes of action across the chemicals [92,100,101]; the quantification of an acceptable boundary of ecotoxicological stress, expressed as mixture toxic pressure level without biodiversity effects; and finally the formulation of results as an overall footprint. Zijp et al. [97] adopted the ecotoxicological threshold value for the exposure of species assemblages, applied in the EU Water Framework Directive and the U.S., that no more than 5\% of species experience low-level chronic effects, which is in regulatory practice assumed to represent the boundary of the safe operating space for chemicals. The final metric provided a quantitative measure of the environmental space (e.g., volume of water) required to dilute emissions from human activities to concentrations such that impacts are smaller than the pre-defined threshold (boundary) of ecotoxicological stress.

A second chemical footprint methodology was developed by Bjørn et al. [98] using a modified version of the UNEP-SETAC global scientific consensus model for characterising ecotoxicological impacts of chemicals in LCA, USEtox $[102,103]$. The two approaches are conceptually similar in the combination of elements from exposure and effects assessment and the boundary definition. USEtox, however, uses a simple additive model for mixture ecotoxicity. The main difference concerns the chemical life-cycle related model design and the associated final toxic pressure metric, expressed here in PAF $\cdot \mathrm{m}^{3} \cdot$ year, explicitly relating to impact on the biosphere integrity, reflecting the fraction of species affected in the ecosystem caused by a chemical emission over a time interval into a volume of water.

Initial experiences with chemical footprint methodologies have highlighted the key challenges inherent in operationalising the chemical pollution boundary, including the high degree of spatial and temporal differentiation needed to adequately account for ecotoxicological impacts in a chemical footprint, particularly for short-lived toxic chemicals [98]. Currently available models and data allow for assessing environmental concentrations and ecotoxicity data for footprint analyses of nearly 2000 data-rich compounds, with swift expansion on the number of chemicals in an ongoing process $[104,105]$. Typically a limited number of chemicals appear to determine the level of impact on biodiversity in a region [106]. Practical evidence, therefore, suggests that many chemicals can be screened out, considering their limited potential to contribute to transgression of a safe chemical stress boundary [102].

\subsection{Further Research}

Chemical footprinting approaches require further evaluation and refinements, including: improving knowledge on the commercial uses and releases of chemicals; assessing exposure levels using more spatially and temporally resolved multi-media models; and reducing the uncertainty associated with chemical toxicity estimates through better understanding of their modes of action and mixture toxicity in realistic, multi-stressed ecosystems. However, a balance will need to be struck 
between improving data quality and increasing data demands. One of the major functions of the current tools may be screening and prioritisation [102].

Localised or regionalised boundaries need to be established for landscapes or watersheds, as for water use (see Section 4), together with further research on setting boundaries based on the disruption and/or alteration of actual ecosystem functions and services (as opposed to arbitrary policy objectives) and on how to aggregate stress effects from the local or regional level up to the planetary level (see Section 7). The links to biosphere integrity and water use (scarcity) are particularly important, considering the contribution of chemicals to affecting biosphere integrity, and considering the role of water volume and dilution in determining chemical risks: water scarcity exacerbates exposure and thus risk. In defining a boundary, research should also focus on the vulnerability of exposed ecosystems [85,107] incorporating the concept of Ecosystem Vulnerability Distributions [108], whereby it matters whether the mixture affects the food web generically, or specifically primarily via sensitive functional groups [109].

\section{Allocation and Governance of the Spaces}

In the case of climate change, the target value for GHG emissions is the outcome of extensive public debate (which conforms loosely with the 'post-normal science' approach; see Section 3.1) on the basis of scientific evidence and socio-economic realities. These deliberations have involved transnational organisations such as UN and IPCC, national governments and non-governmental organisations such as the World Wide Fund for Nature (WWF) and the World Resources Institute (WRI). Even so, the consensus figure of $450 \mathrm{ppm} \mathrm{CO}_{2 \mathrm{e}}$ for the boundary is still regarded by some as contentious. The deliberations have also led to high level governance principles, such as 'contract-and-converge', introduced in Section 3.2, that provide a basis for allocating the space between countries but do not provide a sufficiently specific basis for companies to set strategic targets. Collaborative initiatives such as Science-Based Targets (SBT-see Section 3.2) demonstrate the willingness of some companies to engage in boundary setting, method development and action planning. The SBT initiative attempts to provide a basis by bench-marking GHG reductions against sectorial targets, but contains arbitrary fixed allocations within and between sectors and so removes an important aspect of strategic planning. An alternative basis, avoiding this limitation, is to relate impacts to turnover. Such an approach is available in the Overall Business Impact Assessment (OBIA) methodology in which the impact (e.g., GHG emissions) of a business area is evaluated per unit of economic value and compared with the average for the global economy. OBIA was originally developed by Unilever to assess the environmental performance of business areas, and was subsequently adapted for value chain analysis $[110,111]$. In the PB context, expressing the available 'space' as a permissible impact per unit of economic activity would provide a basis for company targets which recognise the need to remain within the boundary, relating aspirations for expanding markets to technological innovation. UNEP [112] also considers using OBIA, among other examples of LCA at the organisational level, to prioritise actions.

The other three boundaries considered here are further from being rendered operational. The complex scale issues of the other PBs introduces problems in addition to those identified for climate change: governing 'use' of the 'space' requires local or regional management structures and development of cross-sectoral and transboundary working relationships which may not correspond to political boundaries or organisational structures [113-115]. The complexity of 'polycentric' institutional design, funding, cooperation and boundary-spanning to operationalise individual PBs and their interactions is daunting [115].

For freshwater use, suggestions have been made on how to approach the definition of the boundary at a watershed level; the scientific basis in local and regional assessment is set out in Section 4.1. This is sufficient to provide a basis for companies to manage products, processes and production sites. However the definition has yet to be subjected to the same level of public debate as climate change, and approaches to aggregate these watershed level boundaries to provide a single 
planetary indicator are not yet mature. International river basins cover $45 \%$ of the land surface area of the world and supply $60 \%$ of the global freshwater supply [116]. There are 267 international rivers basins and 148 countries whose territory overlaps with at least one international river basin. While use of the waters of international river basins can lead to tensions between countries, outright conflict is rare whereas cooperation between countries over shared water resources is common: at least 688 agreements have been signed between countries to manage shared water resources, including 250 independent freshwater treaties [116]. Of the 217 treaties analysed by Giordano et al. [116], 37\% incorporate some form of water allocation mechanism; most recognise the issue of flow variability and $45 \%$ include some reference to either water quality or environmental issues. Many of the international agreements have established bodies to manage specific shared water resources across political boundaries, with examples on all the inhabited continents [117]. However, the effectiveness of these organisations in governing water allocations and ensuring adequate environmental flows and avoiding ecological tipping points is variable. While mechanisms and organisations are in place for local allocation and governance of access to freshwater resources, there is no pre-eminent body at the international level to ensure consistency of approach. The UN has established UN-Water as the United Nations inter-agency coordinator for all freshwater related issues, with various individual UN agencies working on water issues and sometimes overlapping. Other international bodies include the Global Water Partnership, World Water Council, International Water Resources Association, and the International Water Association. The Global Water Partnership is perhaps the largest of the international organisations in terms of its number of member organisations but it lacks the authority of IPCC as a definitive voice or coordinating body. These international bodies can possibly push for water consumption limits in all river basins that are consistent with the global targets. However, at present, companies have no alternative to fragmented dealings with local bodies.

For biosphere integrity, there is also consensus that local and regional assessment and management are needed, as opposed to a single global approach as for climate change. However, whilst there has been some progress towards defining measures of biodiversity loss that could be used to define boundaries, simple accepted metrics are elusive: whilst the biodiversity crisis is global, biodiversity distribution and its conservation status is hugely variable across the planet [118] while biodiversity itself is a multi-faceted concept (genetic vs. functional) spanning different levels of organization from species to populations to ecosystems. Therefore biodiversity has not been distilled into a small number of global (or even local) indicators [119], although the two proposed proxy indicators and boundaries offered by the PB framework are a promising attempt. This makes the task of governing and allocating the safe operating space even more challenging than for water use. Much as for water use, policy measures for addressing biodiversity loss are in place locally (e.g., Sites of Special Scientific Interest (SSSIs) in Great Britain), and regionally (the Endangered Species Act in the U.S., Ecological 'Red-Lining' in China, biodiversity offsets required for development permits in Mongolia, Colombia, and other countries), but these measures are not based on a consistent global approach. For instance, U.S. policy only considers threat to individual species, not ecosystems (other than protecting habitat in which particular endangered species are found), while China considers a portfolio of representative ecosystems representing the diversity of the whole region. The conceptual framework offered recently by the Intergovernmental Platform on Biodiversity and Ecosystem Services (IPBES) may offer a means to highlight the commonalities in the world's biodiversity and the benefits it provides to humans [118] and so enable local and regional governance and policy measures to be formulated consistently. This is required if the safe operating space is to be allocated at a sufficiently fine scale. At least until a commonly-accepted basis has emerged, companies have no alternative to using proxy metrics for biosphere integrity, of which land use change appears to be the most practical and representative.

For chemicals, various international treaties and national and international bodies have been set up to control and reduce emissions contributing to other planetary boundaries, such as the Montreal Protocol for ozone depletion, as well for global promotion of chemical safety and management at national level, such as the Strategic Approach to International Chemicals Management (SAICM). 
However, such approaches do not address the challenges of multi-scale assessment displayed by the chemicals boundary, in common with water use and biosphere integrity. In addition to the problems arising from discrepancies between scientific and political scales, there is the additional complication that chemicals in products may be traded, used and disposed in multiple locations. For many individual chemicals, the safe space has been defined by setting permissible local concentrations to assure safe environmental quality defined in terms of species presence and ecosystem function. This leads to allocation of the space by the so-called 'zero-allocation option', whereby a company's emissions are restricted or prohibited prior to entering the market to ensure that their realistic worst-case emission levels do not transgress the boundary for any individual chemical. This approach potentially leads to a 'first come, first served' allocation of the space or alternatively would require more complex cross-sectorial discussions of the allocation of the space. Companies are familiar with this type of preventive regulation, and have embedded the associated consequences of (trans)national regulations in their management, e.g., via the obligation under REACH [91] to deliver data and risk assessments according to prescribed scenario calculations aimed at the safe production and use of chemicals.

Synergistic and antagonistic effects between chemicals are problems in developing a single aggregated metric or setting the safe space for the chemical pollution PB. Concentration addition is currently often the responsible and conservative choice to aggregate impacts across chemicals or mixtures and is the approach adopted in chemical footprint case studies $[97,98]$. Despite their underlying uncertainties, existing footprinting approaches can be utilized to establish whether local or regional compartments receive a net chemical load resulting in exposure levels transgressing the safe boundary. Environmental policies are then in place, as a second 'defence layer' adding to the preventive chemical policies, mandating counter-measures to be taken. For example, in the European Water Framework Directive, the absence of a good ecological status or good chemical status results in obligations to design and implement a program of measures in a river basin management plan. A major remaining challenge is to build a consensus on principles and processes for allocating the safe space of e.g., a river basin by considering the potential shares and roles of individuals, companies and governments [120]. With the chemical footprint approach, companies can calculate their contribution to 'filling the environmental space', and take emission-reduction activities accordingly, either via safe product design (consumer-aspects) or via emission reductions measures. The implementation of the 'circular economy' concept might act as an extra trigger by minimising environmental exposure while promoting 'benign by design' chemicals [83], as re-use of materials can result in unexpected human risks elsewhere in the cycling of products.

The problems arising from discrepancies between scientific and political scales underline why multi-national companies are important in moves to recognise and respect the Planetary Boundaries. In a globalised market, their supply chains run across geographical and administrative boundaries and so practical approaches to understanding their geo-spatial contributions and impacts are fundamental in the management of PBs with a regional/local dimension.

\section{The Way Forward}

The Planetary Boundaries framework as specified by Rockström et al. [1] and Steffen et al. [2] represents a major advance in conceptualising the ecological limits to human development and the risks posed by unsustainable production and consumption. The focus here has been on how the PB approach might be applied by businesses with global supply chains in strategic planning, particularly to decouple growth from environmental impact. Our analysis points to four scientific and technical challenges which remain priority areas for further research.

First, only climate change is truly planetary in scale; the other boundaries need to be quantified at a range of geographic scales-local, regional and planetary - defined by natural phenomena rather than political boundaries. Determining the right spatial units for analysis and defining the boundaries 
at an appropriate scale but consistent with a common global basis requires development of a shared system of metrics that can be applied consistently at and across different scales.

Second, a key step in operationalising PBs, particularly for life cycle sustainability assessment, is to set 'distance from boundary' measures. This has been demonstrated for climate change, which manifests on the global scale and for which there is a scientifically agreed way to quantify the boundary, some consensus on its numerical value and an emerging international governance framework. In principle, a precautionary 'distance from boundary' approach could also be used for boundaries characterised by multiple scales. However, this necessitates measurement and decision-making processes that apply at local and regional scales but recognise global targets, as exemplified by the water use boundary.

Third, continued and co-ordinated development of global, preferably open-source, databases and models is a priority, both to evaluate the current status of the earth's systems relative to local, regional and global thresholds and to project future responses to pressures from human activities. This will underpin development of decision-making tools which can be used by companies and other organisations recognising the need to respect absolute sustainability.

Finally, although the PBs are currently treated as distinct, to provide a pragmatic start for designing 'fair-share' principles, the interactions between them must be better understood and the understanding integrated into the three priority research areas outlined above. We have noted some specific examples, such as that between climate change and biosphere integrity, and water use (scarcity), chemical pollution and biosphere integrity. The interactions are mediated in part by human actions (e.g., land-use change induced by changes in agricultural productivity), and therefore do need to be incorporated into company decision-making.

Overlaying the scientific and technical challenges in defining the safe operating space for each PB is the ethical problem of the normative basis for allocating shares of the safe operating space for each company or sector and for generating indicators and evaluation tools [121]. Rather than assuming a share based on current sectorial composition and product portfolios, such as has been proposed for the climate change boundary in the 'Science-Based Targets' approach, there is a case for exploring approaches which are more flexible and therefore more suitable for strategic planning in companies. Relating the available space to economic activity might represent a practical way forward. One possible approach is to normalise impacts against turnover or added value as in the Overall Business Impact Assessment (OBIA) approach discussed in Section 7. The ethical basis for such an approach is currently being explored by some of the present authors.

Part of the motivation for this paper is to identify the challenges and needs of the Planetary Boundaries concept from a business perspective and to provoke discussion. As noted in the Introduction, a further indispensable task is to relate the definition of a humanitarian 'just space' to the social foundations approach outlined by Raworth [5] and Dearing et al. [6] and to the global Sustainable Development Goals agreed by the UN [21]. As noted in Section 2.1, we recognise that this task is even more complex than allocating the environmental space, and requires clear and widely accepted normative principles. Even so, there is a clear need for commercial organisations to act now to recognize the existence of absolute planetary boundaries and to incorporate them into their planning and corporate values and reporting, even if the metrics have not yet achieved universal consensus. For example, sectoral commitments to 'no net deforestation' will contribute to maintaining aspects of biosphere integrity even in the absence of comprehensive measures of biodiversity. This commitment, however, carries some risk that pressure may be increased on the critical area thresholds of other biomes. Such risk represents a difficult potential trade-off, highlighting the importance of maintaining a systems-level perspective and the need for a science and knowledge base that is as complete and comprehensive as possible.

Where governance of the 'safe operating space' is absent or ineffective, there is a particular need for metrics and approaches to measurement and allocation that have a chance of achieving acceptance 
by business and others with the foresight to see that sustaining humankind is dependent on not violating the Planetary Boundaries and is a prerequisite for any future economy.

Acknowledgments: This paper derives from discussion and analysis by the author group initiated at a workshop supported by Unilever's Safety and Environmental Assurance Centre (SEAC) and held in November 2014 at the University of Surrey. Leo Posthuma's attendance was funded by RIVM's strategic project S/607020 under the auspices of RIVM's CEO and Scientific Advisory Board. The views in this article represent a general consensus among the authors and do not necessarily reflect those of the various organizations to which they are affiliated.

Author Contributions: The framing and challenges were defined in the workshop. The following people contributed to these specific topics: Ian Christie, Roland Clift, Dieter Gerten, Henry King and Johan Rockström to the climate change section; Anne-Marie Boulay, Julia Chatterton, Jonathan Chenoweth, Julie Clavreul, Chris France, Dieter Gerten, Mark Goedkoop, Simon Mair, Cynthia Mitchell and Edward Price to the water section; Rebecca Chaplin-Kramer, Fabrice DeClerck, Angela Druckman, Thomas Koellner, Eric Lambin, Llorenc Mila I Canals, Carina Mueller, Richard Murphy and Sarah Sim to the biodiversity section; Roland Clift, Antonio Franco, Michael Hauschild, Mark Huijbregts, Henry King, Jaqi Lee, Stuart Marshall, Michael, McLachlan, Leo Posthuma and James Suckling to the chemicals section. The core writing team included Roland Clift, Sarah Sim, Henry King, Jonathan Chenoweth, Ian Christie, Julie Clavreul, Carina Mueller, Leo Posthuma, Rebecca Chaplin-Kramer, Fabrice DeClerck, Johan Rockström and Richard Murphy.

Conflicts of Interest: The authors declare no conflict of interest.

\section{References}

1. Rockström, J.; Steffen, W.; Noone, K.; Persson, A.; Chapin, F.S.; Lambin, E.F.; Lenton, T.M.; Scheffer, M.; Folke, C.; Schellnhuber, H.J.; et al. A safe operating space for humanity. Nature 2009, 461, 472-475. [CrossRef] [PubMed]

2. Steffen, W.; Richardson, K.; Rockström, J.; Cornell, S.E.; Fetzer, I.; Bennett, E.M.; Biggs, R.; Carpenter, S.R.; de Vries, W.; de Wit, C.A.; et al. Planetary Boundaries: Guiding human development on a changing planet. Science 2015, 347. [CrossRef] [PubMed]

3. Bjørn, A.; Diamond, M.; Owsianiak, M.; Verzat, B.; Hauschild, M.Z. Strengthening the Link between Life Cycle Assessment and Indicators for Absolute Sustainability to Support development within Planetary Boundaries. Environ. Sci. Technol. 2015, 49, 6370-6371. [CrossRef] [PubMed]

4. Hellweg, S.; Milà i Canals, L. Emerging approaches, challenges and opportunities in life cycle assessment. Science 2014, 344, 1109-1113. [CrossRef] [PubMed]

5. Raworth, K. A Safe and Just Space for Humanity. Can We Live within the Doughnut? Oxfam Discussion Paper. 2012. Available online: https:/ /www.oxfam.org/sites/www.oxfam.org/files/dp-a-safe-and-justspace-for-humanity-130212-en.pdf (accessed on 14 December 2016).

6. Dearing, J.A.; Wang, R.; Zhang, K.; Dyke, J.G.; Haberl, H.; Hossain, M.S.; Langdon, P.G.; Lenton, T.M.; Raworth, K.; Brown, S.; et al. Safe and just operating spaces for regional social-ecological systems. Glob. Environ. Chang. 2014, 28, 227-238. [CrossRef]

7. Häyhä, T.; Lucas, P.L.; van Vuuren, D.P.; Cornell, S.E.; Hoff, H. From Planetary Boundaries to national fair shares of the global safe operating space-How can scales be bridged? Glob. Environ. Chang. 2016, 40, 60-72. [CrossRef]

8. Vanderheiden, S. Allocating Ecological Space. J. Soc. Philos. 2009, 40, 257-275. [CrossRef]

9. Kim, R.E.; Bosselmann, K. Operationalizing Sustainable Development: Ecological Integrity as a Grundnorm of International Law. Rev. Eur. Comp. Int. Environ. Law 2015, 24, 194-208. [CrossRef]

10. Greaker, M.; Stoknes, P.E.; Alfsen, K.H.; Erikson, T. A Kantian approach to sustainable development indicators for climate change. Ecol. Econ. 2013, 91, 10-18. [CrossRef]

11. Grasso, M. A normative ethical framework in climate change. Clim. Chang. 2007, 81, 223-246. [CrossRef]

12. Intergovernmental Panel on Climate Change (IPCC). Climate Change 2014: Mitigation of Climate Change (WGIII); Fifth Assessment Report; United Nations Environment Programme: Nairobi, Kenya, 2014.

13. Whiteman, G.; Walker, B.; Perego, P. Planetary boundaries: Ecological foundations for corporate sustainability. J. Manag. Stud. 2013, 50, 307-336. [CrossRef]

14. Van den Bergh, J.; Grazi, F. On the Policy Relevance of Ecological Footprints. Environ. Sci. Technol. 2010, 44, 4843-4844. [CrossRef] [PubMed] 
15. Blomqvist, L.; Brook, B.W.; Ellis, E.C.; Kareiva, P.M.; Nordhaus, T.; Shellenberger, M. Does the Shoe Fit? Real versus Imagined Ecological Footprints. PLoS Biol. 2013, 11. [CrossRef] [PubMed]

16. Galli, A.; Giampietro, M.; Goldfinger, S.; Lazarus, E.; Lin, D.; Saltelli, A.; Wackernagel, M.; Müller, F. Questioning the Ecological Footprint. Ecol. Indic. 2016, 69, 224-232. [CrossRef]

17. Fanning, A.L.; O'Neill, D.W. Tracking resource use relative to planetary boundaries in a steady-state framework: A case study of Canada and Spain. Ecol. Indic. 2016, 69, 836-849. [CrossRef]

18. Planetary Boundaries and Social Thresholds-How Do Companies Measure up? A Practitioner's Perspective. Executive Summary, December 2016, Produced by Article 13. Available online: http:/ /www.article13.com/ research (accessed on 25 January 2017).

19. Nykvist, B.; Persson, A.; Moberg, F.; Persson, L.; Cornell, S.; Rockström, J. National Environmental Performance on Planetary Boundaries, a Study for the Swedish Environmental Protection Agency; Report 6576; Naturvårdsverket: Stockholm, Sweden, 2013.

20. Dao, H.; Friot, D.; Peduzzi, P.; Chatenoux, B.; de Bono, A.; Schwarzer, S. Environmental Limits and Swiss Footprints Based on Planetary Boundaries; UNEP/GRID-Geneva \& University of Geneva: Geneva, Switzerland, 2015.

21. Griggs, D.; Stafford Smith, M.; Rockström, J.; Öhman, M.C.; Gaffney, O.; Glaser, G.; Kanie, N.; Noble, I.; Steffen, W.; Shyamsundar, P. An integrated framework for sustainable development goals. Ecol. Soc. 2014, 19, 49. [CrossRef]

22. Science-Based Targets Website. Available online: http://sciencebasedtargets.org/ (accessed on 14 December 2016).

23. United Nations. Transforming Our World: The 2030 Agenda for Sustainable Development. A/RES/70/1. 2015. Available online: https://sustainabledevelopment.un.org/post2015/transformingourworld (accessed on 14 December 2016).

24. Baumann, H.; Tillman, A.M. The Hitch Hiker's Guide to LCA-An Orientation in Life Cycle Assessment Methodology and Application; Studentlitteratur AB: Lund, Sweden, 2004.

25. Sim, S.; King, H.; Price, E. The Role of Science in Shaping Sustainable Business: Unilever Case Study. In Taking Stock of Industrial Ecology; Clift, R., Druckman, A., Eds.; Springer: Berlin/Heidelberg, Germany, 2016; pp. 291-302.

26. Bjørn, A.; Hauschild, M.Z. Introducing carrying capacity-based normalisation in LCA: Framework and development of references at midpoint level. Int. J. Life Cycle Assess. 2015, 20, 1005-1018. [CrossRef]

27. Murphy, R.J.; King, H.; Sim, S.; Chenoweth, J.; Christie, I.; Clavreul, J.; Lee, J.; Clift, R. Towards Operationalizing the Planetary Boundaries Concept in LCA for Products. In Proceedings of the SETAC Europe 25th Annual Meeting, Barcelona, Spain, 3-7 May 2016; Abstract TU 299. Available online: https://c.ymcdn.com/sites/www.setac.org/resource/resmgr/Abstract_Books/SETAC-Barcelonaabstracts.pdf (accessed on 14 December 2016).

28. Bjørn, A.; Margni, M.; Roy, P.O.; Bulle, C.; Hauschild, M.Z. A proposal to measure absolute environmental sustainability in life cycle assessment. Ecol. Indic. 2016, 63, 1-13. [CrossRef]

29. Bjørn, A.; Bey, N.; Georg, S.; Røpke, I.; Hauschild, M.Z. Is Earth recognised as a finite system in corporate responsibility reporting? J. Clean. Prod. 2016. [CrossRef]

30. Ryberg, M.W.; Owsianiak, M.; Richardson, K.; Hauschild, M.Z. Challenges in implementing a Planetary Boundaries based Life-Cycle Impact Assessment methodology. J. Clean. Prod. 2016, 139, 450-459. [CrossRef]

31. Biggs, R.; Carpenter, S.R.; Brock, W.A. Turning back from the brink: Detecting an impending regime shift in time to avert it. Proc. Natl. Acad. Sci. USA 2009, 106, 826-831. [CrossRef] [PubMed]

32. Scheffer, M.; Bascompte, J.; Brock, W.A.; Brovkin, V.; Carpenter, S.R.; Dakos, V.; Held, H.; van Nes, E.H.; Rietkerk, M.; Sugihara, G. Early-warning signals for critical transitions. Nature 2009, 461, 53-59. [CrossRef] [PubMed]

33. Scheffer, M.; Hirota, M.; Holmgren, M.; van Nes, E.H.; Chapin, F.S., III. Thresholds for boreal biome transitions. Proc. Natl. Acad. Sci. USA 2012, 109, 21384-21389. [CrossRef] [PubMed]

34. Barnosky, A.D.; Hadly, E.A.; Bascompte, J.; Berlow, E.L.; Brown, J.H.; Fortelius, M.; Getz, W.M.; Harte, J.; Hastings, A.; Marquet, P.A.; et al. Approaching a state shift in Earth's biosphere. Nature 2012, 486, 52-58. [CrossRef] [PubMed] 
35. Wang, R.; Dearing, J.A.; Langdon, P.G.; Zhang, E.; Yang, X.; Dakos, V.; Scheffer, M. Flickering gives early warning signals of a critical transition to a eutrophic lake state. Nature 2012, 492, 419-422. [CrossRef] [PubMed]

36. Intergovernmental Panel on Climate Change (IPCC). Climate Change 2013: The Physical Science Basis (WGI); Fifth Assessment Report; United Nations Environment Programme: Nairobi, Kenya, 2013.

37. Intergovernmental Panel on Climate Change (IPCC). Climate Change 2014: Synthesis Report; Fifth Assessment Report; United Nations Environment Programme: Nairobi, Kenya, 2014.

38. Funtowicz, S.O.; Ravetz, J.R. Science for the post-normal age. Futures 1993, 25, 739-755. [CrossRef]

39. Rogelj, J.; Schaeffer, M.; Friedlingstein, P.; Gillett, N.P.; van Vuuren, D.P.; Riahi, K.; Allen, M.; Knutti, R. Differences between carbon budget estimates unravelled. Nat. Clim. Chang. 2016, 6, 245-252. [CrossRef]

40. Royal Commission on Environmental Pollution (RCEP). Energy: The Changing Climate; The Stationery Office: London, UK, 2000.

41. Garnaut, R. The Garnaut Review: Australia in the Global Response to Climate Change; Cambridge University Press: Port Melbourne, Australia, 2011.

42. Hertwich, E.G.; Peters, G.P. $\mathrm{CO}_{2}$ embodied in international trade with implications for global climate policy. Environ. Sci. Technol. 2009, 43, 6414-6420. [CrossRef] [PubMed]

43. ISO 14046: Water Footprint-Principles, Requirements and Guidelines. 2014. Available online: http:/ / www.iso.org/iso/catalogue_detail?csnumber=43263 (accessed on 14 December 2016).

44. Postel, S.L.; Daily, G.C.; Ehrlich, P.R. Human appropriation of renewable fresh water. Science 1996, 271, 785-788. [CrossRef]

45. Gerten, D.; Rockström, J.; Heinke, J.; Steffen, W.; Richardson, K.; Cornell, S. Response to Comment on "Planetary boundaries: Guiding human development on a changing planet". Science 2015, 348, 1217. [CrossRef] [PubMed]

46. Pastor, A.V.; Ludwig, F.; Biemans, H.; Hoff, H.; Kabat, P. Accounting for environmental flow requirements in global water assessments. Hydrol. Earth Syst. Sci. 2014, 18, 5041-5059. [CrossRef]

47. Poff, N.L.; Richter, B.D.; Arthington, A.H.; Bunn, S.E.; Naiman, R.J.; Kendy, E.; Acreman, M.; Apse, C.; Bledsoe, B.P.; Freeman, M.C.; et al. The ecological limits of hydrologic alteration (ELOHA): A new framework for developing regional environmental flow standards. Freshw. Biol. 2010, 55, 147-170. [CrossRef]

48. Berger, M.; van der Ent, R.; Eisner, S.; Bach, V.; Finkbeiner, M. Water Accounting and Vulnerability Evaluation (WAVE): Considering Atmospheric Evaporation Recycling and the Risk of Freshwater Depletion in Water Footprinting. Environ. Sci. Technol. 2014, 48, 4521-4528. [CrossRef] [PubMed]

49. Hoekstra, A.Y.; Mekonnen, M.M.; Chapagain, E.K.; Mathews, R.E.; Richter, B.D. Global monthly water scarcity: Blue water footprints versus blue water availability. PLoS ONE 2012, 7. [CrossRef] [PubMed]

50. Byers, E.A.; Hall, J.W.; Amezaga, J.M. Electricity generation and cooling water use: UK pathways to 2050. Glob. Environ. Chang. 2014, 25, 16-30. [CrossRef]

51. Gerten, D.; Hoff, H.; Rockström, J.; Jägermeyr, J.; Kummu, M.; Pastor, A.V. Towards a revised planetary boundary for consumptive freshwater use: Role of environmental flow requirements. Curr. Opin. Environ. Sustain. 2013, 5, 551-558. [CrossRef]

52. Boulay, A.M.; Bare, J.; Benini, L.; Berger, M.; Lathuilliere, M.; Manzardo, A.; Margni, M.; Motoshita, M.; Nunez, M.; Oki, T.; et al. The WULCA consensus characterization model for water scarcity footprints: Assessing impacts of water consumption based on available water remaining (AWARE). Int. J. Life Cycle Assess. 2017. under review.

53. Milà i Canals, L.; Chenoweth, J.; Chapagain, A.; Orr, S.; Antón, A.; Clift, R. Assessing freshwater use impacts in LCA: Part I-Inventory modelling and characterisation factors for the main impact pathways. Int. J. Life Cycle Assess. 2009, 14, 28-42. [CrossRef]

54. Núnez, M.; Pfister, S.; Roux, P.; Anton, A. Estimating water consumption of potential natural vegetation on global dry lands: Building an LCA framework for green water flows. Environ. Sci. Technol. 2013, 47, 12258-12265. [CrossRef] [PubMed]

55. Quinteiro, P.; Dias, A.C.; Silva, M.; Ridoutt, B.G.; Arroja, L. A contribution to the environmental impact assessment of green water flows. J. Clean. Prod. 2015, 93, 318-329. [CrossRef]

56. Döll, P. Impact of climate change and variability on irrigation requirements: A global perspective. Clim. Chang. 2002, 54, 269-293. [CrossRef] 
57. Menzel, L.; Flörke, M.; Matovelle, A.; Alcamo, J. Impacts of socio-economic development and climate change on water re-sources and water stress. In Proceedings of the 1st International Conference on Adaptative and Integrative Water Management (CAIWA 2007), Basel, Switzerland, 12-15 November 2007.

58. Brook, B.W.; Ellis, E.C.; Perring, M.P.; Mackay, A.W.; Blomqvist, L. Does the terrestrial biosphere have planetary tipping points? Trends Ecol. Evol. 2014, 28, 396-401. [CrossRef] [PubMed]

59. Isbell, F.; Calcagno, V.; Hector, A.; Connolly, J.; Harpole, W.S.; Reich, P.B.; Scherer-Lorenzen, M.; Schmid, B.; Tilman, D.; van Ruijven, J.; et al. High plant diversity is needed to maintain ecosystem services. Nature 2011, 477, 199-202. [CrossRef] [PubMed]

60. Tilman, D.; Downing, J.A. Biodiversity and Stability in Grasslands. Nature 1994, 367, 363-365. [CrossRef]

61. Kiaer, L.P.; Skovgaard, I.M.; Ostergard, H. Grain yield increase in cereal variety mixtures: A meta-analysis of field trials. Field Crops Res. 2009, 114, 361-373. [CrossRef]

62. Hoehn, P.; Tscharntke, T.; Tylianakis, J.M.; Steffan-Dewenter, I. Functional group diversity of bee pollinators increases crop yield. Proc. R. Soc. Lond. Biol. Sci. 2008, 275, 2283-2291. [CrossRef] [PubMed]

63. Letourneau, D.K.; Jedlicka, J.A.; Bothwell, S.G.; Moreno, C.R. Effects of natural enemy biodiversity on the suppression of arthropod herbivores in terrestrial ecosystems. Annu. Rev. Ecol. Evol. Syst. 2009, 40, 573-592. [CrossRef]

64. Levine, J.M.; Adler, P.B.; HilleRisLambers, J. On testing the role of niche differences in stabilizing coexistence. Funct. Ecol. 2008, 22, 934-936. [CrossRef]

65. Quijas, S.; Schmidt, B.; Balvanera, P. Plant diversity enhances provision of ecosystem services: A new synthesis. Basic Appl. Ecol. 2010, 11, 582-593. [CrossRef]

66. Scholes, R.J.; Biggs, R. A biodiversity intactness index. Nature 2005, 434, 45-49. [CrossRef] [PubMed]

67. Newbold, T.; Hudson, L.N.; Hill, S.L.L.; Contu, S.; Lysenko, I.; Senior, R.A.; Börger, L.; Bennett, D.J.; Choimes, A.; Collen, B.; et al. Global effects of land use on local terrestrial biodiversity. Nature 2015, 520, 45-50. [CrossRef] [PubMed]

68. Röös, E.; Patel, M.; Spångberg, J.; Carlsson, G.; Rydhmer, L. Limiting livestock production to pasture and by-products in a search for sustainable diets. Food Policy 2016, 58, 1-13. [CrossRef]

69. Chaudhary, A.; Verones, F.; de Baan, L.; Hellweg, S. Quantifying Land Use Impacts on Biodiversity: Combining Species-Area Models and Vulnerability Indicators. Environ. Sci. Technol. 2015, 49, 9987-9995. [CrossRef] [PubMed]

70. Frischknecht, R.; Fantke, P.; Tschümperlin, L.; Niero, M.; Antón, A.; Bare, J.; Boulay, A.-M.; Cherubini, F.; Hauschild, M.Z.; Henderson, A.; et al. Global guidance on environmental life cycle impact assessment indicators: Progress and case study. Int. J. Life Cycle Assess. 2016, 21, 429-442. [CrossRef]

71. Jolliet, O.; Antón, A.; Boulay, A.M.; Cherubini, F.; Fantke, P.; Levasseur, A.; McKone, T.E.; Michelsen, O.; Milà i Canals, L.; Motoshita, M.; et al. Global guidance on environmental life cycle impact assessment indicators: Recommendation set 1. Int. J. Life Cycle Assess. 2017. under review.

72. Newbold, T.; Hudson, L.N.; Arnell, A.P.; Contu, S.; de Palma, A.; Ferrier, S.; Hill, S.L.L.; Hoskins, A.J.; Lysenko, I.; Phillips, H.R.P.; et al. Has land use pushed terrestrial biodiversity beyond the planetary boundary? A global assessment. Science 2016, 353, 288-291. [CrossRef] [PubMed]

73. PREDICTS Project Website. Available online: www.predicts.org.uk (accessed on 14 December 2016).

74. Alkemade, R.; van Oorschot, M.; Miles, L.; Nellemann, C.; Bakkenes, M.; ten Brink, B. GLOBIO3: A Framework to Investigate Options for Reducing Global Terrestrial Biodiversity Loss. Ecosystems 2009, 12, 374-390. [CrossRef]

75. Mace, G.M.; Reyers, B.; Alkemade, R.; Biggs, R.; Chapin, S.; Cornell, S.E.; Diaz, S.; Jennings, S.; Leadley, P.; Mumbyl, P.J.; et al. Approaches to defining a planetary boundary for biodiversity. Glob. Environ. Chang. 2014, 28, 289-297. [CrossRef]

76. LinkedIn Post by Sarah Cornell. 2016. Available online: https://www.linkedin.com/pulse/some-thoughtsgoing-beyond-global-biodiversity-boundary-sarah-cornell?trk=prof-post (accessed on 14 December 2016).

77. Harfoot, M.B.J.; Newbold, T.; Tittensor, D.P.; Emmott, S.; Hutton, J.; Lyutsarev, V.; Smith, M.J.; Scharlemann, J.P.W.; Purves, D.W. Emergent Global Patterns of Ecosystem Structure and Function from a Mechanistic General Ecosystem Model. PLoS Biol. 2014, 12. [CrossRef] [PubMed]

78. Hudson, L.N.; Newbold, T.; Contu, S.; Hill, S.L.; Lysenko, I.; de Palma, A.; Phillips, H.R.; Senior, R.A.; Bennett, D.J.; Booth, H.; et al. The PREDICTS database: A global database of how local terrestrial biodiversity responds to human impacts. Ecol. Evol. 2014, 4, 4701-4735. [CrossRef] [PubMed] 
79. Curran, M.P.; de Souza, D.M.; Antón, A.; Teixeira, R.F.M.; Michelsen, O.; Vidal-Legaz, B.; Sala, S.; Milà i Canals, L. How well does LCA model land use impacts on biodiversity? A comparison with approaches from ecology and conservation. Environ. Sci. Technol. 2016, 50, 2782-2795. [CrossRef] [PubMed]

80. National Academy of Science (NAS). Advancing Land Change Modelling: Opportunities and Research Requirements; National Academy of Science: Washington, DC, USA, 2013.

81. Chaplin-Kramer, R.; Sharp, R.P.; Mandle, L.; Sim, S.; Johnson, J.; Butnar, I.; Milà i Canals, L.; Eichelberger, B.A.; Ramler, I.; Mueller, C.; et al. Spatial patterns of agricultural expansion determine impacts on biodiversity and carbon storage. Proc. Natl. Acad. Sci. USA 2015, 112, 7402-7407. [CrossRef] [PubMed]

82. Chaplin-Kramer, R.; Sim, S.; Hamel, P.; Bryant, B.; Noe, R.; Mueller, C.; Rigarlsford, G.; Kulak, M.; Kowal, V.; Sharp, R.; et al. Life Cycle Assessment Needs Predictive Spatial Modelling for Biodiversity and Ecosystem Services. Nat. Comm. 2017, accepted.

83. Geiser, K. Chemicals without Harm. Policies for a Sustainable World; MIT Press: Cambridge, MA, USA, 2015.

84. Persson, L.M.; Breitholtz, M.; Cousins, I.T.; de Wit, C.A.; MacLeod, M.; McLachlan, M.S. Confronting unknown planetary boundary threats from chemical pollution. Environ. Sci. Technol. 2013, 47, 12619-12622. [CrossRef] [PubMed]

85. Zijp, M.C.; Posthuma, L. Towards a Boundary or Footprint for Chemical Pollution; Society of Environmental Toxicology and Chemistry: Berlin, German, 2012.

86. Posthuma, L.; Bjørn, A.; Zijp, M.C.; Birkved, M.; Diamond, M.L.; Hauschild, M.Z.; Huijbregts, M.A.J.; Mulder, C.; van de Meent, D. Chemical footprints-Thin boundaries support environmental quality management. Environ. Sci. Technol. 2014, 48, 13025-13026. [CrossRef] [PubMed]

87. U.S. NRC. Risk Assessment in the Federal Government: Managing the Process; The National Academies Press: Washington, DC, USA, 1983.

88. Stephan, C.E.; Mount, D.I.; Hansen, D.J.; Gentile, J.H.; Chapman, G.A.; Brungs, W.A. Guidelines for Deriving Numerical National Water Quality Criteria for the Protection of Aquatic Organisms and Their Uses; United States Environmental Protection Agency: Duluth MN, USA, 1985.

89. Van Straalen, N.M.; Denneman, C.A.J. Ecotoxicological evaluation of soil quality criteria. Ecotoxicol. Environ. Saf. 1989, 18, 241-251. [CrossRef]

90. Posthuma, L.; Suter, G.W.I.; Traas, T.P. Species Sensitivity Distributions in Ecotoxicology; CRC-Press: Boca Raton, FL, USA, 2002.

91. European Commission (EC). Regulation (EC) No 1907/2006 of the European Parliament and of the Council of 18 December 2006 Concerning the Registration, Evaluation, Authorisation and Restriction of Chemicals (REACH); European Commission: Brussels, Belgium, 2006.

92. De Zwart, D.; Posthuma, L. Complex mixture toxicity for single and multiple species: Proposed methodologies. Environ. Toxicol. Chem. 2005, 24, 2665-2676. [CrossRef] [PubMed]

93. Scientific Committee on Health and Environmental Risks; Scientific Committee on Emerging and Newly Identified Health Risks; Scientific Committee on Consumer Safety. Opinion on the Toxicity and Assessment of Chemical Mixtures; European Commission: Brussels, Belgium, 2012; Available online: http:/ /ec.europa.eu/ health//sites/health/files/scientific_committees/environmental_risks/docs/scher_o_155.pdf (accessed on 14 December 2016).

94. MacLeod, M.; Breitholtz, M.; Cousins, I.T.; deWit, C.A.; Persson, L.M.; Rudén, C.; McLachlan, M.S. Identifying chemicals that are planetary boundary threats. Environ. Sci. Technol. 2014, 48, 11057-11063. [CrossRef] [PubMed]

95. Diamond, M.; de Wit, C.A.; Molander, S.; Scheringer, M.; Backhaus, T.; Arvidsson, R.; Bergman, Å.; Hauschild, M.; Holoubek, I.; Lohmann, R.; et al. Exploring the planetary boundary for chemical pollution. Environ. Int. 2015, 78, 8-15. [CrossRef] [PubMed]

96. GreenScreen Chemicals Website. The GreenScreen Method. Available online: http://www. greenscreenchemicals.org/method (accessed on 14 December 2016).

97. Zijp, M.C.; Posthuma, L.; van de Meent, D. Definition and applications of a versatile chemical pollution footprint methodology. Environ. Sci. Technol. 2014, 48, 10588-10597. [CrossRef] [PubMed]

98. Bjørn, A.; Diamond, M.; Birkved, M.; Hauschild, M.Z. Chemical footprint method for improved communication of freshwater ecotoxicity impacts in the context of ecological limits. Environ. Sci. Technol. 2014, 48, 13253-13262. [CrossRef] [PubMed] 
99. Hoekstra, A.Y.; Chapagain, A.K.; Aldaya, M.M.; Mekonnen, M.M. Water Footprint Manual. State of the Art 2009; Water Footprint Network: Enschede, The Netherlands, 2009; Available online: http:/ / waterfootprint. org/media/downloads/WaterFootprintManual2009.pdf (accessed on 14 December 2016).

100. Posthuma, L.; de Zwart, D. Predicted effects of toxicant mixtures are confirmed by changes in fish species assemblages in Ohio, USA, rivers. Environ. Toxicol. Chem. 2006, 25, 1094-1105. [CrossRef] [PubMed]

101. Posthuma, L.; de Zwart, D. Predicted mixture toxic pressure relates to observed fraction of benthic macrofauna species impacted by contaminant mixtures. Environ. Toxicol. Chem. 2012, 31, 2175-2188. [CrossRef] [PubMed]

102. Rosenbaum, R.K.; Bachmann, T.M.; Gold, L.S.; Huijbregts, M.A.J.; Jolliet, O.; Juraske, R.; Koehler, A.; Larsen, H.F.; MacLeod, M.; Margni, M.; et al. USEtox-The UNEP-SETAC toxicity model: Recommended characterisation factors for human toxicity and freshwater ecotoxicity in life cycle impact assessment. Int. J. Life Cycle Assess. 2008, 13, 532-546. [CrossRef]

103. USEtox 2.0 Website. Available online: http://www.usetox.org (accessed on 14 December 2016).

104. Müller, N.; de Zwart, D.; Hauschild, M.; Kijko, G.; Fantke, P. Exploring REACH as a potential data source for characterizing ecotoxicity in life cycle assessment. Environ. Toxicol. Chem. 2016. [CrossRef] [PubMed]

105. Posthuma, L.; de Zwart, D.; Osté, L.; van der Oost, R.; Postma, J. Water System Analysis with the Ecological Key Factor 'Toxicity'. Part 1: System, Underpinning and Applications; STOWA Report; Stichting Toegepast Onderzoek Waterbeheer: Amersfoort, The Netherlands, 2016.

106. Backhaus, T.; Karlsson, M. Screening level mixture risk assessment of pharmaceuticals in STP effluents. Water Res. 2014, 49, 157-165. [CrossRef] [PubMed]

107. Sala, S.; Goralczyk, M. Chemical footprint: A methodological framework for bridging life cycle assessment and planetary boundaries for chemical pollution. Integr. Environ. Assess. Manag. 2013, 9, 623-632. [CrossRef] [PubMed]

108. Posthuma, L.; Bjørn, A.; Zijp, M.C.; Birkved, M.; Diamond, M.L.; Hauschild, M.Z.; Huijbregts, M.A.J.; Mulder, C.; van de Meent, D. Beyond safe operating space: Finding chemical footprinting feasible. Environ. Sci. Technol. 2014, 48, 6057-6059. [CrossRef] [PubMed]

109. Mulder, C.; Boit, A.; Mori, S.; Vonk, J.A.; Dyer, S.D.; Faggiano, L.; Geisen, S.; González, A.L.; Kaspari, M.; Lavorel, S.; et al. Distributional (in)congruence of biodiversity-ecosystem functioning. Adv. Ecol. Res. 2012, $46,1-88$.

110. Clift, R. Metrics for Supply Chain Sustainability. Clean Technol. Environ. Policy 2003, 5, 240-247. [CrossRef]

111. Clift, R.; Wright, L. Relationships between Environmental Impacts and Added Value along the Supply Chain. Technol. Forecast. Soc. Chang. 2000, 65, 281-295. [CrossRef]

112. United Nations Environment Programme. Guidance on Organizational Life Cycle Assessment; UNEP/SETAC Life Cycle Initiative: Paris, France, 2015.

113. Carley, M.; Christie, I. Managing Sustainable Development, 2nd ed.; Earthscan: London, UK, 2000.

114. Von Heland, F.; Crona, B.; Fidelman, P. Mediating science and action across multiple boundaries in the Coral Triangle. Glob. Environ. Chang. 2014, 29, 53-64. [CrossRef]

115. Galaz, V.; Crona, B.; Osterblom, H.; Olsson, P.; Folke, C. Polycentric systems and interacting planetary boundaries-Emerging governance of climate change-ocean acidification-marine biodiversity. Ecol. Econ. 2012, 81, 21-32. [CrossRef]

116. Giordano, M.; Drieschova, A.; Duncan, J.A.; Sayama, Y.; de Stefano, L.; Wolf, A.T. A review of the evolution and state of transboundary freshwater treaties. Int. Environ. Agreem. Politics Law Econ. 2013, 13, $245-264$. [CrossRef]

117. Schmeier, S.; Gerlak, A.K.; Blumstein, S. Clearing the muddy waters of shared watercourses governance: Conceptualizing international River Basin Organizations. Int. Environ. Agreem. Politics Law Econ. 2016, 16, 597-619. [CrossRef]

118. Diaz, S.; Demissew, S.; Joly, C.; Lonsdale, W.M.; Larigauderie, A. A Rossetta Stone for nature's benefits to people. PLoS Biol. 2015, 13, e1002040. [CrossRef] [PubMed]

119. Turnhout, E.; Dewulf, A.; Hulme, M. What does policy-relevant global environmental knowledge do? The cases of climate and biodiversity. Curr. Opin. Environ. Sustain. 2016, 18, 65-72. [CrossRef] 
120. Carr, G. Stakeholder and public participation in river basin management-An introduction. WIREs Water 2015, 2, 393-405. [CrossRef] [PubMed]

121. Fredericks, S.E. Measuring and Evaluating Sustainability: Ethics in Sustainability Indexes; Routledge: Abingdon, UK, 2014.

(c)

(C) 2017 by the authors; licensee MDPI, Basel, Switzerland. This article is an open access article distributed under the terms and conditions of the Creative Commons Attribution (CC BY) license (http:/ / creativecommons.org/licenses/by/4.0/). 